\title{
Glutamyl-tRNA in Bacteria. Multiple Identities for Multiple Functions ${ }^{\dagger}$
}

\author{
Assaf Katz* and Omar Orellana* \\ Programa de Biología Celular y Molecular, Instituto de Ciencias Biomédicas, Facultad de Medicina, Universidad de
} Chile, Independencia 1027, Santiago 8380453, Chile

\begin{abstract}
The existence of aminoacyl-tRNAs was predicted during the late 50s as molecules that transfer specific amino acids for protein synthesis. Today we know that, in addition to protein synthesis, these molecules can also participate in several other cellular functions. One of these aminoacyl-tRNAs, glutamyl-tRNA, can participate in at least three functions in bacteria: biosynthesis of glutaminyl-tRNA, tetrapyrroles and proteins. In this article we discuss how bacterial cells manage to distribute glutamyltRNA among all these functions. Proteins involved in each pathway recognize different features of the tRNA which allows them to use only the correct glutamyl-tRNA species. Also, the formation of macromolecular complexes allows the utilization of each of these species by the correct proteins. This compartmentalization is critical for bacterial fitness as it prevents the incorporation of intermediates in the incorrect pathway.(doi: 10.5562/cca1830)
\end{abstract}

Keywords: tRNA ${ }^{\text {Glu }}$, molecular recognition, glutamyl-tRNA synthetase, amido transferase, elongation factor Tu, glutamyl-tRNA reductase

\section{Introduction}

The existence and functionality of aminoacyl-tRNAs (aa-tRNAs) was predicted during the late 50s as part of the "adaptor hypothesis" to explain the translation of the genetic message from nucleic acids to amino acids into proteins. This hypothesis proposed that the function of the adaptor (all aa-tRNA) was to transfer the activated amino acid to the nascent peptide in the ribosome. ${ }^{1}$ Today we know that several aa-tRNAs play roles also in other metabolic pathways. ${ }^{2-4}$ Among these aa-tRNAs, glutamyl-tRNA (Glu-tRNA) is a special case, as many organisms use it for two metabolic pathways beside translation: the synthesis of glutaminyl-tRNA (GlntRNA) and the synthesis of tetrapyrroles like heme and chlorophyll (Figure 1). In most bacteria, where all these metabolic routes take place, the alternative pathways must compete with elongator factor $\mathrm{Tu}(\mathrm{EF}-\mathrm{Tu})$ of the translation machinery for their common substrate. Also,

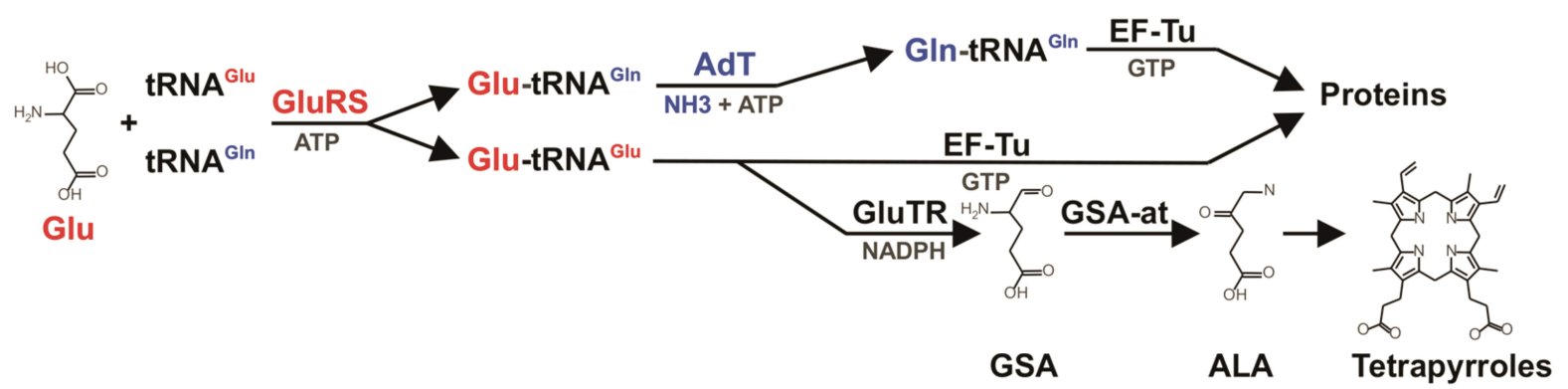

Figure 1. Metabolism of Glu-tRNA in most bacteria. Schematic representation of metabolic routes where Glu-tRNA participates in bacteria. Glu-tRNA synthesis is catalyzed by GluRS. If GluRS uses a tRNA ${ }^{\mathrm{Gln}}$, then AdT catalyze the addition of an amido group and EF-Tu can take the produced Gln-tRNA ${ }^{\mathrm{Gln}}$ for protein synthesis. Otherwise, if GluRS synthesize Glu-tRNA ${ }^{\mathrm{Glu}}$, EF-Tu can directly use it for translation. Also, part of this Glu-tRNA ${ }^{\text {Glu }}$ can be used for tetrapyrrole synthesis through the $\mathrm{C}_{5}$ pathway where ALA synthesis is catalyzed by GluTR and GSA-at.

\footnotetext{
$\dagger$ This article belongs to the Special Issue Chemistry of Living Systems devoted to the intersection of chemistry with life.

* Authors to whom correspondence should be addressed. (E-mail: katz-zondek.1@osu.edu, oorellan@med.uchile.cl)
} 


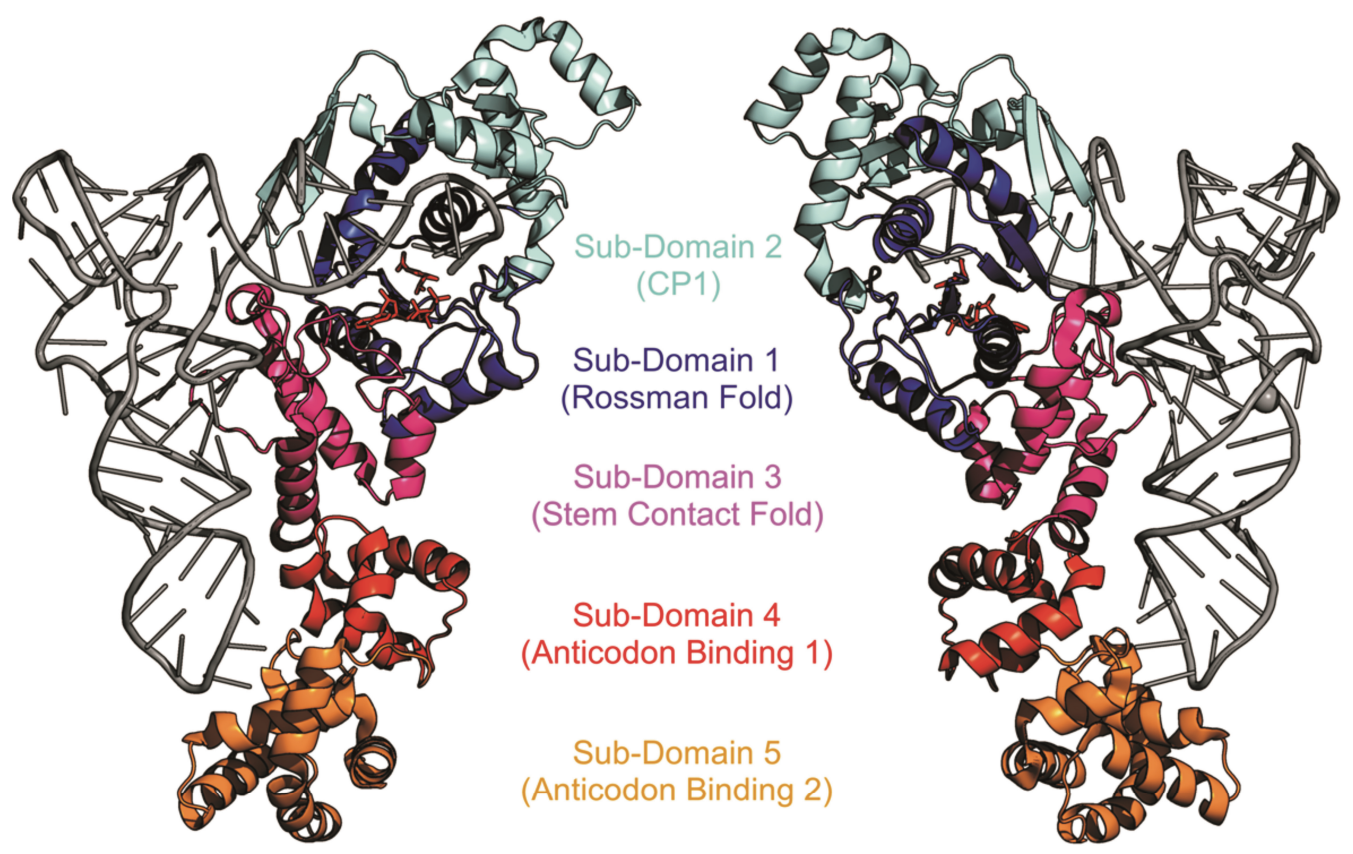

Figure 2. Structure of T. thermophilus GluRS complexed to tRNA ${ }^{\text {Glu }}$, ATP and L-glutamol. Schematic representation of the structure of GluRS from T. thermophilus complexed with tRNA ${ }^{\text {Glu }}$, ATP and L-glutamol (pdb 2DXI). tRNA is in gray while ATP and L-glutamol are in red. Sub-domians 1, 2, 3, 4 and 5 from GluRS are highlighted in blue, cyan, pink, orange and yellow respectively.

in these organisms the regulation of Glu-tRNA synthesis must reflect the requirements of the three pathways, as changes in the Glu-tRNA concentration might produce adverse effects for the cell, either changing the rate of translation or favoring the incorporation of errors during protein synthesis. In this article we discuss current ideas about how Glu-tRNA is recognized for each of these pathways in bacteria and how the Glu-tRNA pool is distributed among its different functions.

\section{Synthesis of Glu-tRNA in Bacteria}

Synthesis of Glu-tRNA is catalyzed by glutamyl-tRNA synthetase (GluRS) which attaches glutamate (Glu) to the $3^{\prime}$ end of tRNA in a two step reaction represented by the following equations:

$$
\begin{aligned}
& \mathrm{ATP}+\mathrm{Glu} \rightarrow \mathrm{Glu}-\mathrm{AMP}+\mathrm{PPi} \\
& \mathrm{Glu}-\mathrm{AMP}+\mathrm{tRNA} \rightarrow \mathrm{Glu}-\mathrm{tRNA}+\mathrm{AMP}
\end{aligned}
$$

Recognition of tRNA by GluRS occurs through contacts distributed over the entire enzyme, which is composed of a catalytic domain (CD) and an anticodon binding domain (ABD). The enzyme belongs to the class I type of aminoacyl-tRNA synthetases (aaRS) and thus, its CD is composed mainly by a Rossman fold (sub-domain 1) that contains two conserved amino acid motifs that recognize the ATP substrate (HIGH and KMSKS). Two other subdomains are contained in the
CD: the "connective peptide 1" (CP1) (sub-domain 2) that interrupts the Rossman fold in most class I aaRS and the stem-contact fold (SC) (sub-domain 3) that joins the $\mathrm{CD}$ and $\mathrm{ABD}$. Although the $\mathrm{CD}$ is conserved throughout all known GluRSs, two different structures are found for the ABD. All bacterial and organellar GluRSs have an ABD composed of two $\alpha$-helix domains (sub-domains 4 and 5) (Figure 2) while the archaeal and eukaryal GluRSs contain an ABD composed mainly of $\beta$-sheets. ${ }^{5-8}$

Activation of Glu with ATP by GluRS occurs only if the tRNA is bound to the enzyme, in a similar manner as has been observed for GlnRS, ArgRS and the class I LysRS. This is partly due to the fact that the CCA at the 3' end of tRNA forms part of the active site and interacts directly with the Glu substrate. Also the binding of the anticodon of tRNA to the ABD induces conformational changes that are transduced to the active site allowing the correct positioning of Glu and ATP which otherwise bind the enzyme in a non productive mode. ${ }^{9-11}$ Correspondingly, aminoa-cylation of tRNA by a truncated GluRS that lacks its ABD, occurs with 400 to 1000 times lower $k_{\text {cat }}$ for aminoacylation compared to the wild type enzyme. ${ }^{12,13}$ Also, charging a tRNA $^{\text {Glu }}$ that lacks its anticodon arm is much less efficient than charging the complete tRNA. ${ }^{14}$ Conversely, a paralog from GluRS called GluQRS naturally lacks an ABD, but presents a "normal" $k_{\text {cat }}$ value for the aminoacylation of the hypermodified nucleoside queuosine located at position 34 of the anticodon from 


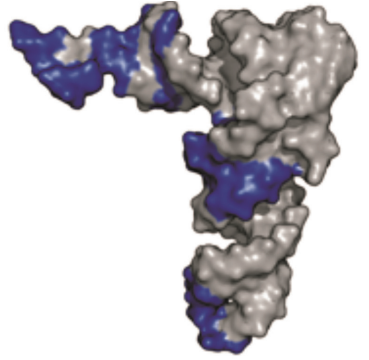

A
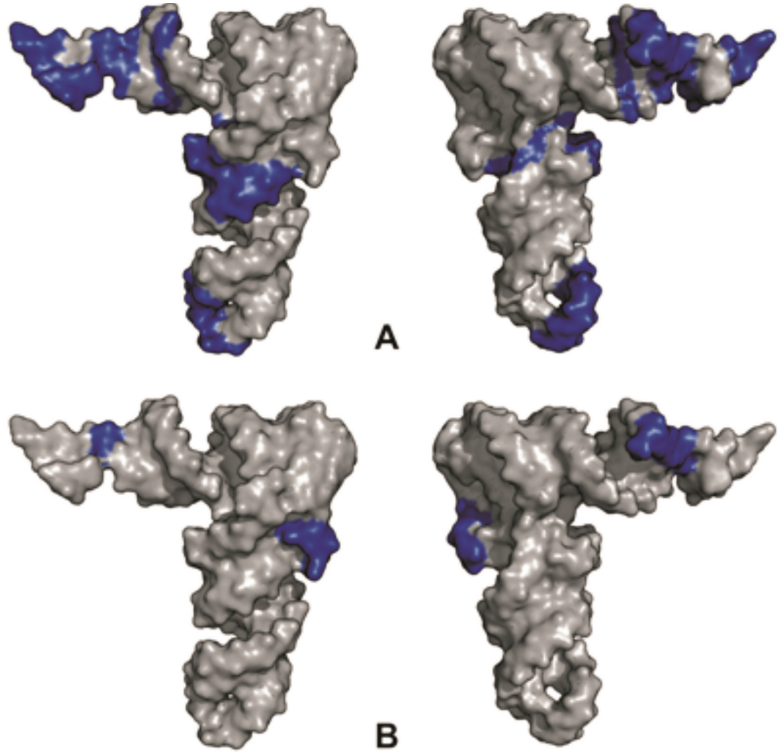

B
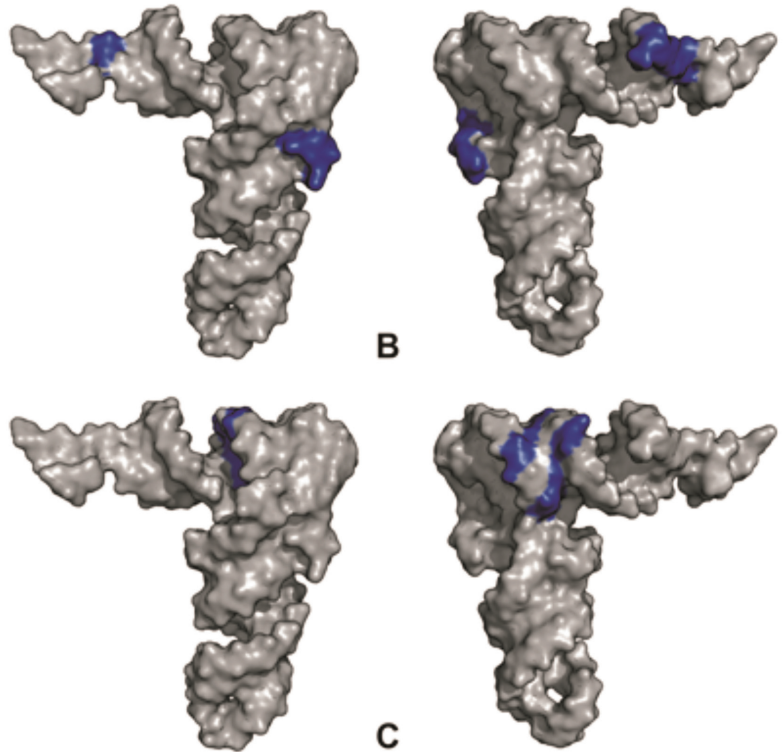

C
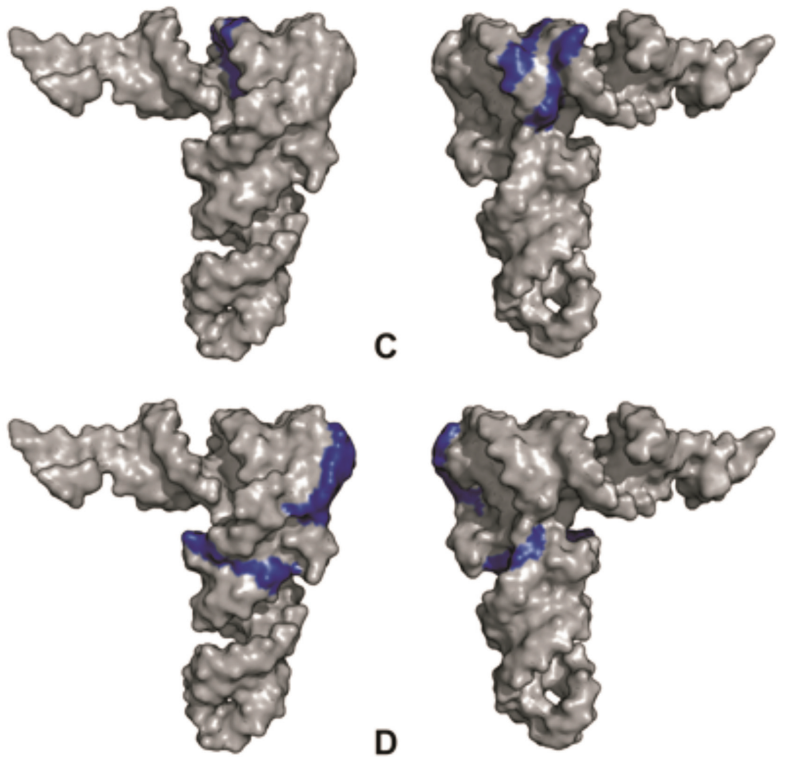

Figure 3. $\mathrm{tRNA}^{\mathrm{Glu}}$ recognition. The surface of $\mathrm{tRNA}^{\mathrm{Glu}}$ from T. thermophilus (pdb 2DXI) is represented in gray. Surface of nucleotides from tRNA ${ }^{\text {Glu }}$ which correspond to E. coli GluRS identity elements (A), anti-determinants suggested for AdT (B), sites relevant for EF-Tu affinity (C) or for the maintenance of the structure of tRNA ${ }^{\text {Glu }}$ recognized by GluTR (D) are highlighted in blue.

tRNA $^{\text {Asp }}$. Also, in contrast to what is observed for GluRS, this enzyme is able to activate glutamate in the absence of tRNA. ${ }^{15-18}$

Based on biochemical studies with E. coli GluRS, it has been shown that the enzyme recognizes the tRNA through specific nucleotides called identity determinants. The key feature recognized by $E$. coli GluRS in tRNA $^{\text {Glu }}$ is the so-called "augmented D helix", which is formed by the D stem and the variable loop together with other neighboring bases in the tertiary structure. From the augmented D helix, U11.A24 base pair seems to be the most relevant feature, although $\psi 13 \cdot \mathrm{G} 22 \cdot \mathrm{A} 46$ bases triple, $\mathrm{C} 4 \cdot \mathrm{G} 69$ base pair, $\mathrm{C} 12 \cdot \mathrm{G} 23 \cdot \mathrm{C} 9$ bases triple and the absence of nucleotide 47 in the variable loop (normally found in other tRNAs, but not in tRNA $^{\text {Glu }}$ ) are also relevant. Other important but weaker identity determinants of $E$. coli tRNA ${ }^{\text {Glu }}$ are nucleotides $\mathrm{U} 34, \mathrm{U} 35, \mathrm{C} 36$ and A37 at the anticodon loop, the 2thio modification of $\mathrm{U} 34$ and the $\mathrm{G} 1 \cdot \mathrm{C} 72$ and $\mathrm{U} 2 \cdot \mathrm{A} 71$ base pairs of the acceptor stem (Figures 3A, 4A). ${ }^{19,20}$ Crystallographic data showed that $T$. thermophilus GluRS binds tRNA ${ }^{\text {Glu }}$ through interactions of the ABD with the anticodon loop, the SC with the D arm and the anticodon stem, as well as interactions of the Rossmann fold and CP1 with the acceptor stem of the tRNA. As a result of the conformational changes induced by the binding of ATP or Glu, some variations in the tRNA contacts are evidenced, mainly the formation of new hydrogen bonds of the tRNA acceptor stem with CP1 and of A76 with both substrates, ATP and glutamate. 9,10 These structural data confirm that the most relevant features recognized by GluRS in the tRNA are located in the augmented D helix, the acceptor arm and the anticodon arm.

\section{Role of GluRS in the Synthesis of GIn-tRNA ${ }^{\text {Gln }}$}

It is now widely accepted that ancient life forms did not have any glutaminyl-tRNA synthetase (GlnRS) to charge tRNA ${ }^{\text {Gln }}$ with glutamine. Instead, this function was accomplished by an indirect pathway composed of two steps. First, a non discriminating GluRS (NDGluRS) charged tRNA ${ }^{\text {Gln }}$ with glutamate and then a tRNA-dependent amidotransferase (AdT) added the amino group to the $\gamma$ carboxylic acid of the glutamate bound to the tRNA (Figure 1). This indirect pathway remains today in all known archaea, ${ }^{21}$ as well as in most bacteria $^{22}$ and eukaryal organelles. ${ }^{23-25}$ Eukaryotic cytoplasm and some bacteria use a direct pathway for GlntRNA $^{\text {Gln }}$ synthesis. This pathway requires a GlnRS that specifically charges tRNA ${ }^{\text {Gln }}$ with glutamine. GlnRS evolved from a duplicated GluRS in eukarya through successive mutations that allowed aminoacylation with glutamine instead of glutamate and restricted its specificity for tRNA ${ }^{\mathrm{Gln}}$ while rejecting tRNA ${ }^{\text {Glu }}$. Following the emergence of GlnRS in eukaryotes, the gene would have been acquired by some bacteria through lateral transfer. This model for enzyme evolution would explain the fact that bacterial GlnRS, where present, has a $\beta$ type ABD that is very similar to the ABD of the archeal/eukaryal GluRS, but different from the bacterial GluRS which has an $\alpha$ type ABD. ${ }^{6,26-28}$

As described above, most bacteria synthesize GlntRNA $^{\text {Gln }}$ through the indirect pathway and with the participation of a GluRS that accomplishes the 
aminoacylation of both tRNA ${ }^{\text {Glu }}$ and tRNA ${ }^{\text {Gln }}$. It has also been observed that some bacteria, like H. pylori and $A$. ferrooxidans, contain two GluRS that specifically charge a different subset of tRNAs. For example, in H. pylori GluRS1 aminoacylates only tRNA ${ }^{\text {Glu }}$ while GluRS2 is specific for tRNA ${ }^{\text {Gln }}$. This specificity has led to the hypothesis that the duplication of GluRS enforces the fidelity of translation and could represent an aborted or ongoing attempt to evolve a bacterial GlnRS. ${ }^{29,30}$ Nevertheless, in A. ferrooxidans, where several tRNA ${ }^{\text {Glu }}$ and tRNA ${ }^{\text {Gln }}$ exist, there is a different specificity pattern since GluRS1 aminoacylates all tRNA ${ }^{\text {Glu }}$ and at least one tRNA ${ }^{\text {Gln }}$ while GluRS2 preferentially aminoacylates a different tRNA ${ }^{\mathrm{Gln}} \cdot{ }^{29}$ This specificity pattern does not support the idea that GluRS duplication enhances specificity of translation as each GluRS charges a different tRNA $^{\text {Gln }}$. Instead, it has been proposed that duplication of GluRS in A. ferrooxidans might be involved in the modulation of tetrapyrole biosynthesis as Glu-tRNA is also used for its synthesis in this bacterium (see below). ${ }^{31}$ As in A. ferrooxidans each GluRS aminoacylates a subset of tRNA ${ }^{\text {Gln }}$ that decodes different glutamine codons, modulation of enzyme expression or activity could produce changes in the relative concentration of each Gln-tRNA ${ }^{\text {Gln }}$ isotype which could differentially affect the translation rate of mRNAs depending on their specific glutamine codon usage. Thus, an alternative unexplored hypothesis is that the duplication of GluRS in A. ferrooxidans might have a role in the regulation of global translation.

\section{Recognition of tRNA by ND-GluRS}

Specificity determinants recognized by the discriminating GluRS (D-GluRS) have been studied mainly in $E$. coli where GluRS charges only tRNA ${ }^{\text {Glu }}$ and not tRNA $^{\mathrm{Gln}}$. In organisms where there is no GlnRS, NDGluRS recognizes and charges both tRNA ${ }^{\text {Glu }}$ and tRNA $^{\text {Gln }}$. This relaxed recognition of tRNA by the NDGluRS may be the consequence of differences at the tRNA $^{\text {Gln }}$, the GluRS itself or both compared with what has been observed in organisms that use the direct pathway for the synthesis of Gln-tRNA ${ }^{\text {Gln }}$. Most reported differences in tRNA recognition are due to changes at the enzyme level. Nevertheless, the fact that some ND-GluRSs charge only tRNA ${ }^{\text {Glu }}$ or tRNA ${ }^{\text {Gln }}$ from $E$. coli (that contains only discriminating enzymes) ${ }^{32,33}$ suggests that some differences between tRNA ${ }^{\mathrm{Glu}}$ and tRNA $^{\text {Gln }}$ must be suppressed in order to allow GluRS to be non-discriminant.

The most evident difference between tRNA ${ }^{\text {Glu }}$ and tRNA $^{\text {Gln }}$ is nucleotide 36 at the anticodon which is $\mathrm{C}$ in tRNA $^{\text {Glu }}$ and $\mathrm{G}$ in tRNA ${ }^{\mathrm{Gln}}$. In T. thermophilus GluRS, the conserved Arg358 in the ABD specifically recognizes $\mathrm{C} 36$ of tRNA ${ }^{\text {Glu }}$ while preventing the binding of
G36 from tRNA ${ }^{\text {Gln }}$ due to steric hindrance and lack of hydrogen bond formation. The presence of a smaller amino acid in the position equivalent to Arg358 in most ND-GluRS prevents the steric clash and allows recognition of both $\mathrm{C} 36$ from tRNA ${ }^{\text {Glu }}$ and G36 of tRNA $^{\text {Gln }}{ }^{{ }^{7,12,34-36}}$ Substitution of Gln373 in the NDGluRS from Bacillus subtilis with Arg, as normally found in D-GluRS, prevents the aminoacylation of tRNA $^{\text {Gln }}$ while preserving the charging of tRNA ${ }^{\text {Glu }}$, thus confirming its relevance in the discrimination of the tRNA anticodon. ${ }^{33}$

The acceptance of G36 by ND-GluRS is not sufficient for recognition of tRNA ${ }^{\mathrm{Gln}}$ and other features that determine its rejection by D-GluRS also must be recognized. This idea is confirmed both by the fact that changing the conserved Arg350 in D-GluRS1 from H. pylori by the Glu commonly found in ND-GluRS is not enough to allow the recognition of tRNA ${ }^{\text {Gln }}$ (Ref. 36) and also because the $\mathrm{CD}$ from $E$. coli GluRS can discriminate between tRNA ${ }^{\text {Glu }}$ and tRNA ${ }^{\text {Gln }}$ even if it is separated from its $\mathrm{ABD} .{ }^{12}$ Concordantly, GluQRS is able to recognize its tRNA substrate although it lacks an ABD. This recognition is achieved through recognition of nucleotides in the anticodon stem and loop that mimics the acceptor stem of tRNA ${ }^{\text {Glu }} \cdot{ }^{17,37}$ A detailed study of the identity determinants recognized by GluRS2 from $H$. pylori (which only charges tRNA ${ }^{\text {Gin }}$ ) showed that the nucleotides of the augmented $\mathrm{D}$ helix from $\mathrm{RRNA}^{\mathrm{Gln}}$ are not critical for tRNA recognition. Instead, this enzyme selects $\mathrm{tRNA} \mathrm{G}^{\mathrm{Gln}}$ mainly through identity elements located in the acceptor stem (base pairs U1.A72 and G5. C68)(Figure 4B) ${ }^{38}$ Accordingly, the crystal structure of tRNA ${ }^{\text {Gln }}$ bound to the ND-GluRS from Thermotoga maritima (pdb 3AKZ) $)^{35}$ revealed that the enzyme forms fewer hydrogen bonds with the D stem of the tRNA and more with the acceptor stem when compared with the contacts between D-GluRS of T. thermophilus and its tRNA $^{\text {Glu }}$ (pdb 2CV2) (Figures 4C and 4D). Conversely, as explained above $A$. ferrooxidans has two GluRS that can be classified as non-discriminating since each one charges tRNA ${ }^{\mathrm{Gln}}$. When the D stem of a tRNA substrate of GluRS1 from A. ferrooxidans is reduced from four to three base pairs, the tRNA is no longer a substrate of the enzyme $^{39}$ suggesting that the relaxed recognition of the augmented D helix is not the strategy for nondiscrimination by this enzyme.

Thus, the data reviewed here suggest that most ND-GluRS are relaxed in their recognition of the augmented D helix and nucleotide 36 of the anticodon loop. Instead, these enzymes recognize the tRNA through identity elements located in the acceptor stem plus some nucleotides in the anticodon loop. Nevertheless, this seems not to be a general rule as ND-GluRS1 from $A$. ferrooxidans might retain important identity elements in 
A.

Identity elements of D-GluRS from E. coli

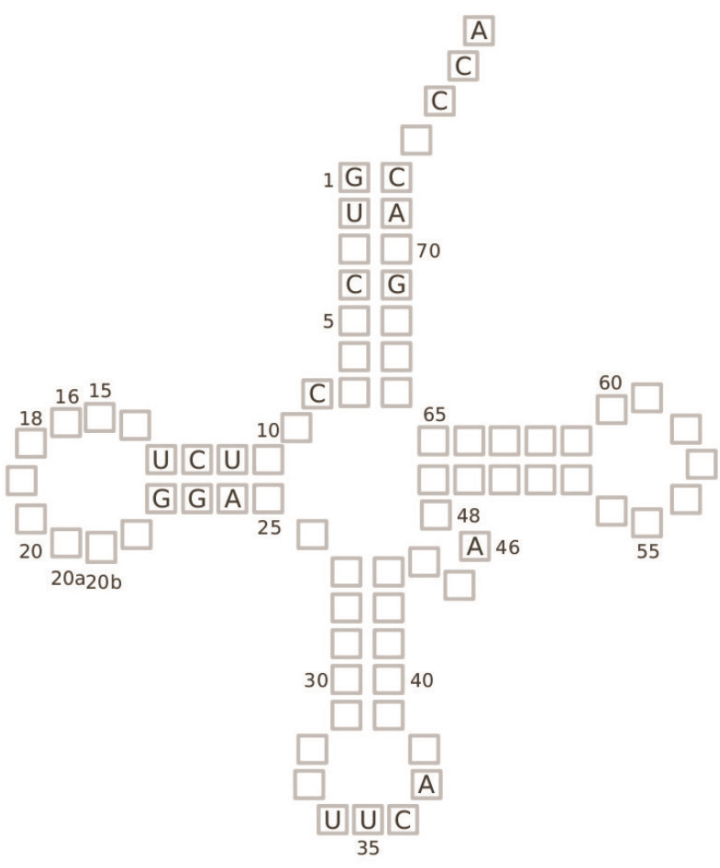

C.

Contacts with D-GluRS from T. thermophilus
B.

Identity elements of ND-GluRS from $\boldsymbol{H}$. pylori

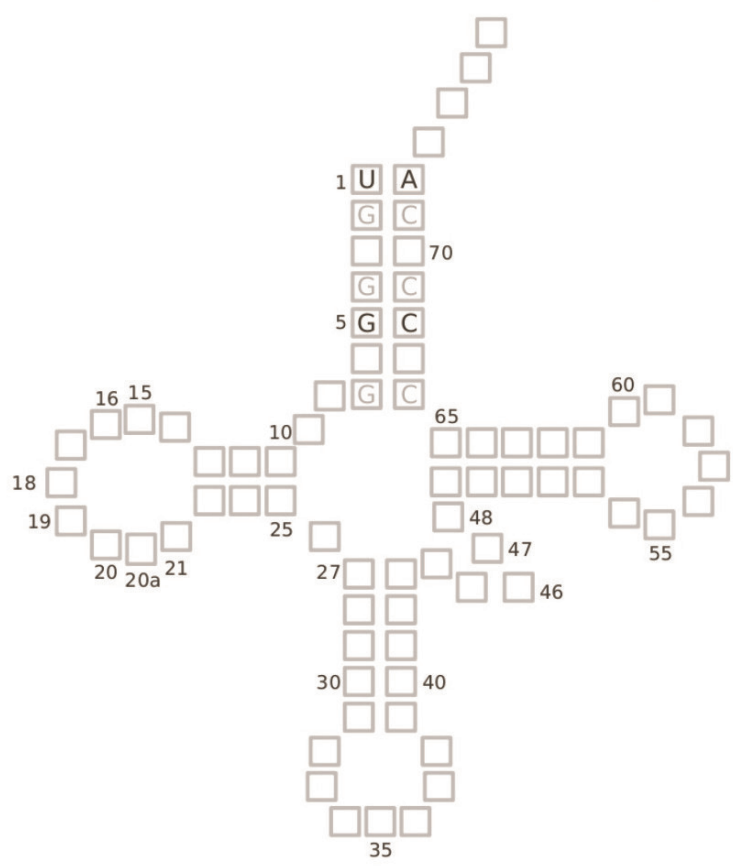

D.

Contacts with ND-GluRS from T. maritima
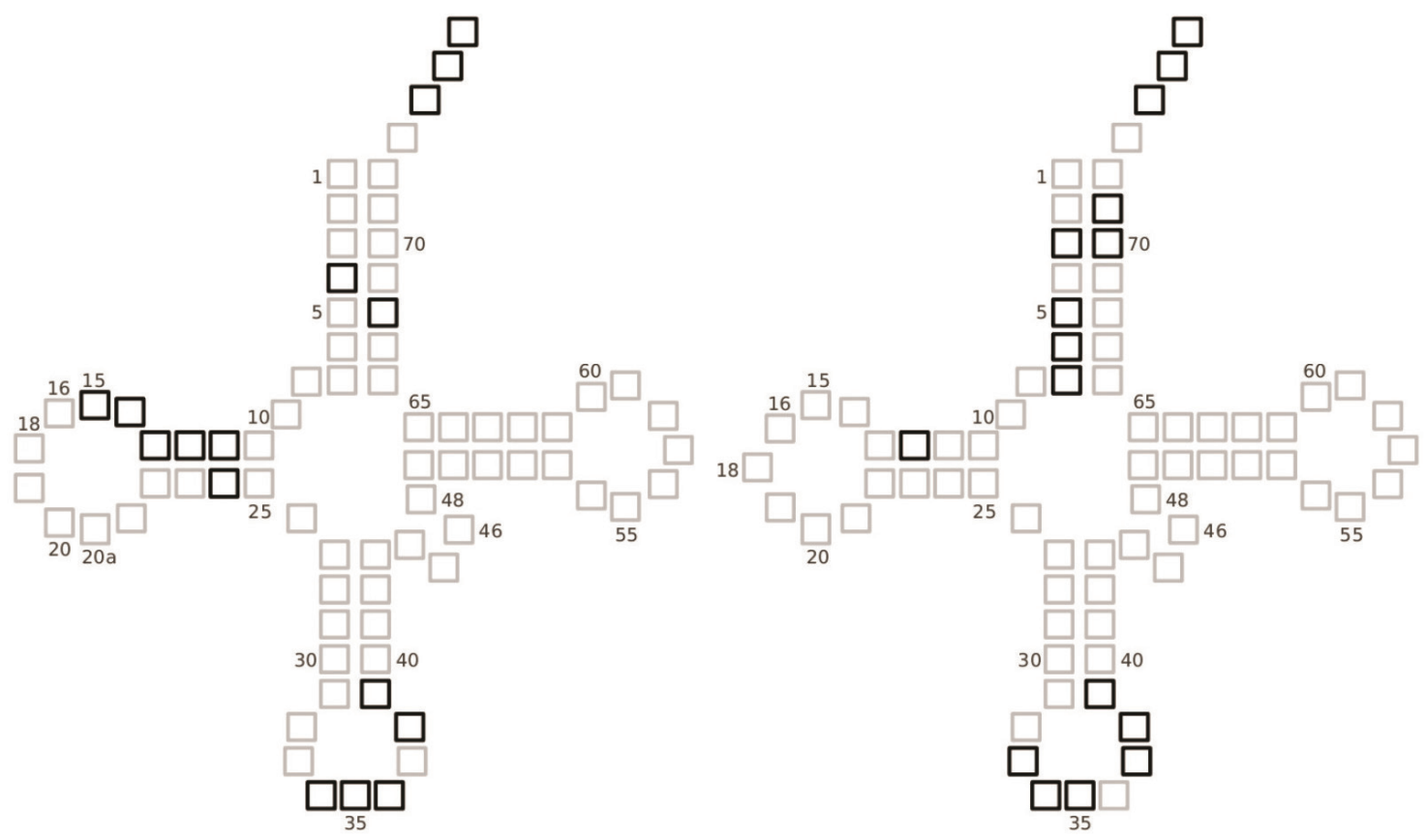

Figure 4. Comparison of the tRNA identity elements recognized by discriminating and non-discriminating GluRS. Upper panel: biochemically determined identity elements for E. coli D-GluRS (A) and H. pylori ND-GluRS2 (B). Black and gray letters represent confirmed and suggested identity elements respectively. Lower panel: schematic representation of the contacts between DGluRS and tRNA Glu from T. thermophilus (C) (pdb 2CV2) and between ND-GluRS and tRNA Gln from T. maritima (D) (pdb 3AKZ). Black boxes represent tRNA nucleotides that form a hydrogen bond with the enzyme. Data calculated using PDBePISA v1.18 was obtained from www.pdbe.org. ${ }^{93}$ Only contacts present in both chains of pdb $2 \mathrm{CV} 2$ or in at least three out of four chains of pdb $3 \mathrm{AKZ}$ were considered. 
the augmented D helix. Further studies will be required in order to determine which is the mechanism used for non-discrimination in $A$. ferrooxidans GluRS1 and how conserved are both mechanisms throughout bacteria.

\section{Synthesis of Gln-tRNA ${ }^{\text {Gln }}$ from Glu-tRNA ${ }^{\text {Gln }}$}

The indirect pathway for the synthesis of Gln-tRNA ${ }^{\text {Gln }}$ requires the transformation of the glutamate moiety from Glu-tRNA ${ }^{\text {Gln }}$, synthesized by the ND-GluRS, into glutamine (Figure 1). Several bacteria and archaea use a similar indirect pathway for the synthesis of AsntRNA $^{\text {Asn }}$ from Asp-tRNA ${ }^{\text {Asn }}$ synthesized by a NDAspRS. Both indirect pathways require an AdT that transfers an amine group to the free carboxylic acid of the amino acid bound to tRNA. Three types of AdT exist: a hetero trimeric GatCAB enzyme present in bacteria, archaea and eukaryal organelles, a hetero dimeric GatDE enzyme found only in archaea and a hetero trimeric GatFAB in which A and B subunits are very similar to those from GatCAB and that is found in mitochondria from yeast and other fungi. ${ }^{25,40} \mathrm{GatDE}$ and GatFAB only catalyzes the formation of Gln-tRNA ${ }^{\text {Gln }}$ while GatCAB can catalyze the formation of GlntRNA $^{\text {Gln }}$ and Asn-tRNA ${ }^{\text {Asn }}$. The reaction catalyzed by GatCAB in vivo depends on the presence of GlnRS and ND-GluRS or AsnRS and ND-AspRS respectively. ${ }^{40}$ Nevertheless, the sole presence of GlnRS and/or AsnRS does not rule out the existence of the indirect pathway as both pathways may coexist. For example, in $T$. thermophilus and Deinococcus radiodurans AsntRNA $^{\text {Asn }}$ is synthesized by both AsnRS and the indirect pathway using a ND-AspRS and GatCAB. Aparently the main role for the coexistence of both pathways is to ensure asparagine synthesis as both organisms lack a tRNA independent asparagine synthetase. ${ }^{41,42}$

Amidation of Glu and Asp by either GatCAB or GatDE occurs in various steps that are localized in the different subunits of the enzymes. In the first step, GatA or GatD catalyze the formation of ammonia $\left(\mathrm{NH}_{3}\right)$ mainly from Gln or Asn, although ammonium $\left(\mathrm{NH}_{4}^{+}\right)$ can also be used as the ammonia source. ${ }^{22,40,43-47}$ Ammonia is then transferred to the active site of either GatB or GatE through a channel protected from the solvent. ${ }^{40,45,46}$ In GatB and GatE, the free carboxylic acid of the tRNA-bound amino acid is first activated through an ATP dependent phosphorylation and then transamidated using the ammonia generated by GatA or GatE. ${ }^{40,44-46}$ GatC from GatCAB has no proven catalytic activity involved in the amidotrasferase reaction. Instead the protein acts as a chaperone for correct expression and folding of GatA. ${ }^{22,40}$

Glu-tRNA $^{\text {Gln }}$ and Asp-tRNA ${ }^{\text {Asn }}$ are naturally formed as intermediates in the indirect pathway. These "mis-acylated tRNAs" represent a potential danger for protein synthesis as they can incorporate an acidic ami- no acid in the position where an amide (neutral) should be in the nascent peptide. The main mechanism to prevent this mis-incorporation seems to be the formation of the "transamidosome", a complex between AdT, the tRNA and the ND-aaRS which avoids the release of the mis-acylated tRNA to the cytoplasm before the amide is formed. ${ }^{48-50}$ A second barrier for the incorporation of mis-acylated Glu-tRNA ${ }^{\text {Gln }}$ and Asp-tRNA ${ }^{\text {Asn }}$ is the discrimination by EF-Tu that preferentially binds correctly aminoacylated tRNAs while rejecting most of misacylated ones. ${ }^{39,42,51-55}$ This combined strategy effectively prevents the mis-incorporation of Glu or Asp instead of Gln or Asn in nascent peptides.

\section{Recognition of tRNA in the Transamidosome}

Bacterial AdT (GatCAB) forms the transamidosome with ND-GluRS and ND-AspRS..$^{35,48,50,56}$ In these complexes, the AdT must unambiguously recognize GlutRNA $^{\text {Gln }}$ and Asp-tRNA ${ }^{\text {Asn }}$ instead of the correctly charged Glu-tRNA ${ }^{\text {Glu }}$ and Asp-tRNA ${ }^{\text {Asp }}$. In the complex the two enzymes cannot use the same identity elements simultaneously. Thus, only one enzyme can bind to the acceptor stem of tRNA to catalyze either aminoacylation or amidation. In order to recognize the tRNA the enzymes use unshared identity elements. GluRS or AspRS bind to the anticodon arm whereas AdT binds to the $\mathrm{D}$ arm. The absence of nucleotides 20A and 20B in tRNA ${ }^{\text {Gln }}$ and tRNA ${ }^{\text {Asn }}$ induces a special conformation of the D loop that allows AdT to discriminate them from tRNA ${ }^{\text {Glu }}$ and $\mathrm{tRNA}^{\mathrm{Asp}}$ respectively. Conformational changes of all components of the transamidosome (aa-tRNA, aaRS and AdT) allows the acceptor stem of the tRNA to change from one active site to the other. When localized in AdT, the tRNA is recognized also by the $\mathrm{U} 1 \cdot \mathrm{A} 72$ base pair that in bacteria is only present in tRNA ${ }^{\text {Gln }}$ and tRNA ${ }^{\text {Asn }}$, representing a second identity element for the enzyme (Figure $3 \mathrm{~B}$ and 5). ${ }^{35,48,50,56-58}$

The transamidosome is a low stability complex (Kd value of $\approx 40 \mu \mathrm{mol} \mathrm{dm}{ }^{-3}$ in $H$. pylori). This low stability appears to allow the big structural changes that are required for the movement of the acceptor stem of the tRNA between the active site of both enzymes. Also it accounts for the fact that the tRNA has to easily leave the complex to enter protein translation. ${ }^{50}$ Crystal structures of transamidosomes from thermophiles have been obtained, ${ }^{35,56}$ although in the case of the complex from T. maritima it was necessary to covalently link NDGluRS to GatC in order to obtain structural data. ${ }^{35}$ Interestingly, the general structure of transdamidosomes GluRS-GatCAB from T. maritima and AspRS-GatCAB from $T$. thermophilus differ considerably. While the GluRS-GatCAB complex is formed by one GluRS, one GatCAB and one tRNA substrate, ${ }^{35}$ the AspRS-GatCAB complex is supposed to be formed in solution by one 

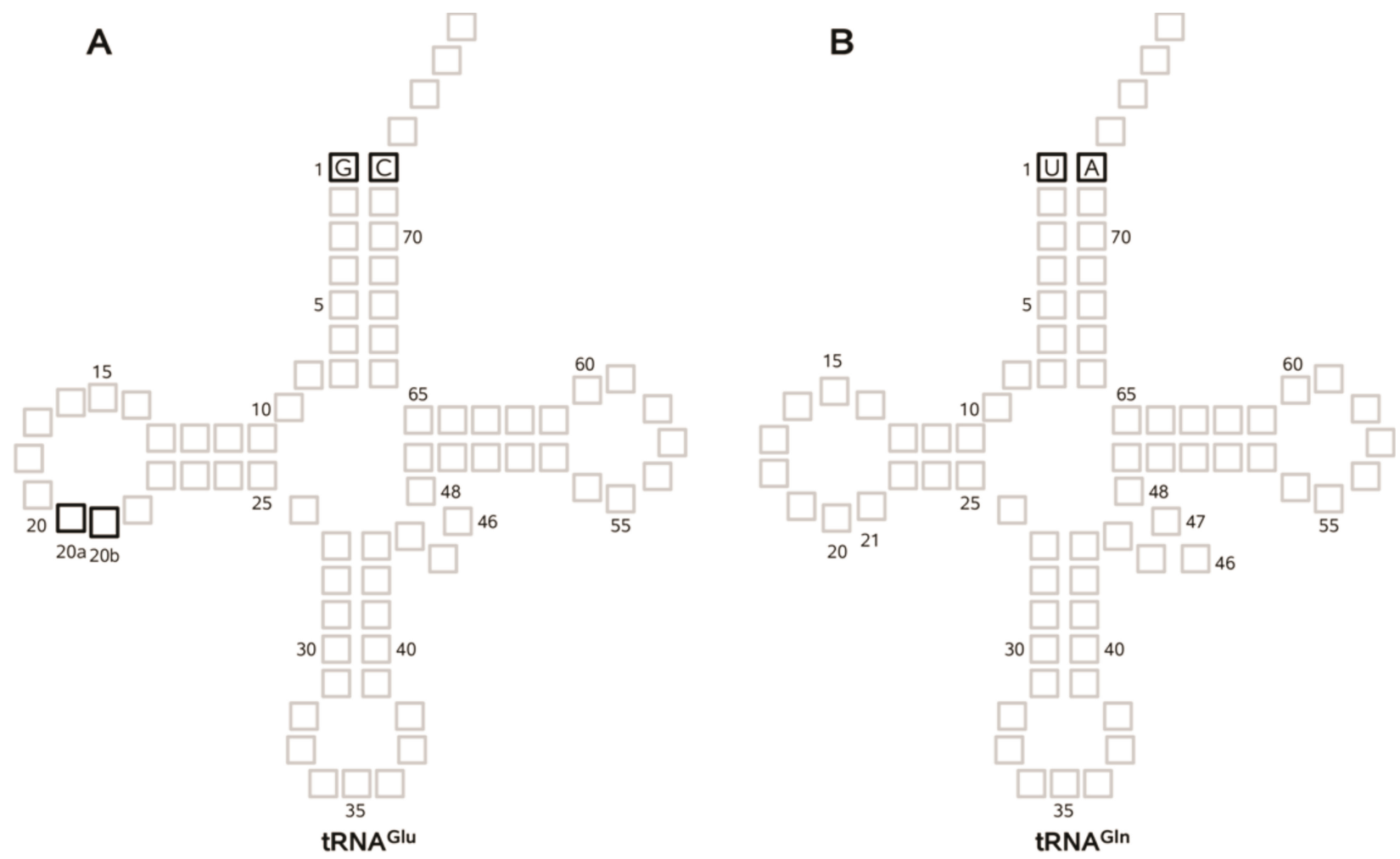

Figure 5. Identity elements for AdT. (A) Proposed identity anti-determinants of tRNA ${ }^{\text {Glu }}$ for bacterial AdT are marked in black boxes and the corresponding base indicated when corresponding. (B) Proposed identity determinants of tRNA ${ }^{\text {Gln }}$ for bacterial AdT are marked in black boxes with the corresponding base indicated. ${ }^{57}$

AspRS dimer, two GatCAB and two tRNAs. Surprisingly, one of these tRNA is catalytically active, but the other one has a structural role stabilizing the complex. ${ }^{56}$ A similar complex between ND-GluRS and GatDE has been proposed in the archaea Methanothermobacter thermautotrophicus. ${ }^{49}$ Nevertheless, other groups have not been able to reproduce these results and kinetic experiments indicate that there is no channeling of GlutRNA ${ }^{\text {Gln }}$ between the two enzymes. ${ }^{55}$ Thus, further research is needed to confirm whether in archaea the usage of Glu-tRNA ${ }^{\text {Gln }}$ for translation is prevented only by EF-Tu discrimination or there is also a role played by a transamidosome.

\section{EF-Tu as a Final Barrier against Incorporation of mis-acylated tRNAs during Protein Translation}

The natural role of EF-Tu is to deliver all aa-tRNAs into the ribosome independently of the amino acid attached to the 3 'end of tRNA. In order to perform this function, EF-Tu binds all tRNAs mainly through non-specific contacts to the backbone of the acceptor and T $\Psi \mathrm{C}$ stems and has a spacious binding site to accommodate any of the amino acids used in translation apart of fMet. ${ }^{52,59,60}$ Based on these characteristics it is surprising that EF-Tu is able to discriminate between correctly and noncorrectly aminoacylated tRNAs, preventing the incorpo- ration of Glu-tRNA ${ }^{\text {Gln }}$, Asp-tRNA Asn and other misacylated tRNAs during translation. ${ }^{39,42,51-54}$ As a general mechanism, discrimination is obtained thanks to a thermodynamic compensation between the contributions of tRNA and the amino acid to the binding free energy $(\Delta G)$. In correctly aminoacylated-tRNAs two scenarios can occur. Where binding of the tRNA to EF-Tu presents high affinity, the contribution of the amino acid is rather small. Conversely, when the tRNA binding has low affinity, the amino acid has a larger contribution to the global binding $\Delta G$. Thus, all correctly charged tRNAs bind similarly to EF-Tu even though the tRNAs and the amino acids may have different affinities for the protein. In mis-acylated tRNAs the contribution of the tRNA and the amino acid result in a molecule that either binds too weakly or too tightly to EF-Tu preventing an efficient incorporation of the aa-tRNA in translation. ${ }^{61,62}$ Both, Glu-tRNA ${ }^{\text {Gln }}$ and Asp-tRNA ${ }^{\text {Asn }}$ bind to EF-Tu with a much lower affinity than the correctly acylated tRNAs. ${ }^{42,51-53}$ In the cases of tRNA ${ }^{\text {Asp }}$ and tRNA ${ }^{\text {Asn }}$ (and probably also for tRNA ${ }^{\mathrm{Glu}}$ and tRNA ${ }^{\mathrm{Gln}}$ ) discrimination between the tRNAs is carried out by the recognition of the 49.65 and 51.63 base pairs located at the TYC stem (Figures 3 and 6). The presence of a $U$ in the 49.65 base pair allows a high affinity binding while its presence in the 51.63 base pair produces the inverse effect (low affinity binding). $\mathrm{tRNA}^{\mathrm{Gln}}$ and $\mathrm{RRNA}^{\mathrm{Asn}}$ generally pre- 


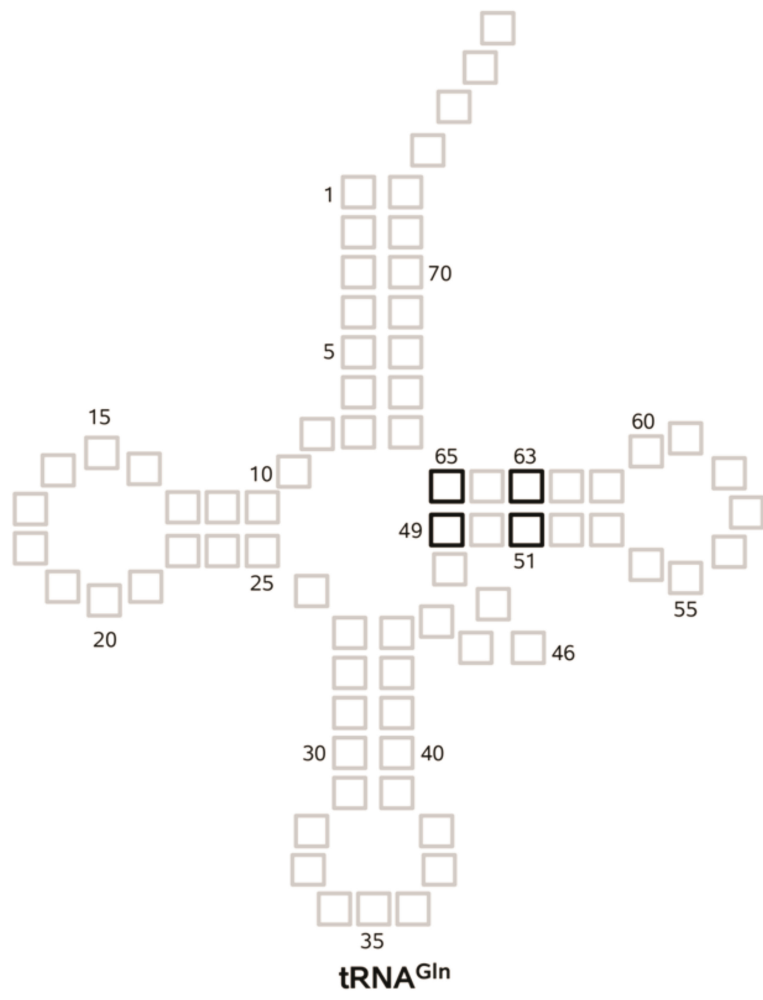

Figure 6. Nucleotides relevant for Glu-tRNA ${ }^{\text {Gln }}$ rejection by EF-Tu. Nucleotides that have been proposed to be relevant for Glu-tRNA ${ }^{\text {Gln }}$ rejection by EF-Tu are highlighted in black boxes. $^{52}$

sent a $U$ in the 51.63 base pair but not in the 49.65 base pair and thus, these tRNAs have low affinity for EF-Tu. On the other hand, Glu and Asp bind with low affinity to EF-Tu due to the presence of E227 (using $T$. thermophilus EF-Tu numbering). Thus, tRNA ${ }^{\mathrm{Gln}}$ and tRNA $^{\text {Asn }}$ bind to EF-Tu with an affinity compatible with protein synthesis only when they carry Gln or Asn, which are amino acids that bind EF-Tu with high affinity. 52

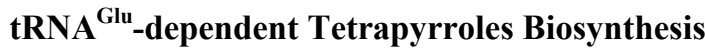

Tetrapyrroles such as heme, chlorophyll and cobalamine are synthesized from $\delta$-aminolevulinic acid (ALA) through a pathway that is conserved in all organisms. Nevertheless, ALA may be synthesized through two different pathways. In $\alpha$-proteobacteria and nonphotosynthetic eukaryotic organisms ALA is synthesized by the $\mathrm{C}_{4}$ or Shemin pathway from glycine and succinyl-CoA in a one step condensation reaction catalyzed by ALA-synthase. All other bacteria, as well as all archaea and chloroplasts, synthesize ALA through the $\mathrm{C}_{5}$ or glutamate pathway. In this pathway, the glutamate moiety from Glu-tRNA ${ }^{\text {Glu }}$ is reduced and detached from the tRNA by glutamyl-tRNA reductase (GluTR) that uses NADPH as the reducing agent. This reaction forms glutamate-1-semialdehyde (GSA) that is finally isomerized to ALA by GSA aminotransferase (GSA-at) in a pyridoxal 5'-phosphate dependent reaction (Figure 1). ${ }^{63,64}$

In solution, GluTR is a dimer ${ }^{65-68}$ which, based on crystalographic studies, presents a particular "V" shape (pdb 1GPJ). Each subunit that forms the "arms" of the $\mathrm{V}$ is composed of a three domain monomer arranged along a curved "spinal" $\alpha$-helix of about $110 \AA$. The dimerization domain is localized at the carboxyterminus of the polypeptide forming the base of the $\mathrm{V}$, while the catalytic and NADPH binding domains are localized in the other extreme of the $\mathrm{V}^{69}$ In vivo, dimeric GluTR is part of a larger complex along with a dimer of GSA-at that is positioned in the cavity of the $\mathrm{V}$ formed by GluTR. The function of this complex would be to channel GSA between the two enzymes preventing its degradation by side reactions with water. ${ }^{64,69-71}$

Glu-tRNA $^{\text {Glu }}$, but not Glu-tRNA ${ }^{\text {Gln }}$, is a substrate of GluTR ${ }^{14,72,73}$ which may represent a protective mechanism that prevents the use of Gln-tRNA ${ }^{\text {Gln }}$ by GluTR since the enzyme cannot efficiently discriminate between Glu and Gln bound to the tRNA. ${ }^{74}$ E. coli GluTR recognizes Glu-tRNA ${ }^{\text {Glu }}$ by the presence of the $\mathrm{U} 13 \cdot \mathrm{G} 22 \cdot \mathrm{A} 46$ base triplet, the G19.C56 tertiary base pair and the absence of nucleotide 47 . Recognition of the tRNA by this enzyme is independent of the identity of the bases in these positions as long as the three dimensional pairings are conserved (Figure 3D). These data, together with other experimental evidence, led Randau and collaborators to propose that GluTR recognize the central core structure of Glu-tRNA ${ }^{\text {Glu }}$ and not specific nucleotides that represent "classical" identity elements. $^{14}$

\section{Sharing Glu-tRNA ${ }^{\text {Glu }}$ between Two Metabolic Path- ways}

Glu-tRNA $^{\text {Glu }}$ is substrate for both protein and tetrapyrrole biosynthesis. Consequently, it has to be distributed among these two pathways to fulfill the ever changing requirements of the cell. Nevertheless, translation generally demands more substrate than tetrapyrrole synthesis. Thus, the fraction of Glu-tRNA used by GluTR depends mainly on its activity, its abundance and the ability of the cell to compartmentalize the pathways channeling the substrate. The cellular concentration of GluTR can be controlled at the transcriptional level $^{75-77}$ and also by the modulation of the enzyme stability in $\gamma$-proteobacteria. ${ }^{78,79}$ GluTR from E. coli and Salmonella typhimurium are degraded by Lon and ClpAP proteases when there is an excess of heme. ${ }^{80}$ The proposed mechanism is that binding of heme to GluTR exposes a hidden proteolysis signal located at the amino terminus of the enzyme enhancing its degradation. ${ }^{79,81}$ Binding of heme to GluTR has also been shown to in- 
hibit enzyme activity in A. ferrooxidans GluTR. ${ }^{68}$ In this bacterium, modulation of Glu-tRNA ${ }^{\text {Glu }}$ synthesis by GluRS1 seems to complement the regulation of GluTR. As $A$. ferrooxidans produces high levels of heme (up to $\approx 6$ times more than E. coli), the control of GluRS1 might be necessary in order to prevent a decrease in Glu-tRNA ${ }^{\text {Glu }}$ levels when tetrapyrrole requirements increase. ${ }^{31}$ The exact mechanism of GluRS1 modulation in A. ferrooxidans has not been determined. An involvement of free radicals derived from tetrapyrroles has been proposed based on the enzyme sensitivity to $\mathrm{H}_{2} \mathrm{O}_{2}$ and the fact that addition of exogenous reduced glutathione partially prevents the inactivation of GluRS1 under culture conditions that increase the intracellular heme concentration. ${ }^{31,82}$

In bacteria, EF-Tu sequesters aa-tRNAs to transfer them to ribosomes for protein translation and protect them from deacylation. Due to the high abundance of EF$\mathrm{Tu}$, it is assumed that there is virtually no free correctly aminoacylated tRNA in the bacterial cytoplasm. Thus, GluTR must compete with EF-Tu for their common substrate. As the cytoplasmic concentration of GluTR is lower than EF-Tu, the discovery of a complex between GluRS, Glu-tRNA ${ }^{\text {Glu }}$ and GluTR seemed to explain how part of Glu-tRNA ${ }^{\text {Glu }}$ is diverted from protein translation to tetrapyrrole biosynthesis. ${ }^{83,84}$ It has not been possible to confirm that the complex between GluRS and GluTR is formed in vivo. ${ }^{71}$ Nevertheless, it has been shown that EF-Tu can deliver aa-tRNA to pathways outside the ribosome. ${ }^{85}$ Thus, the possibility that GluTR receives its GlutRNA $^{\text {Glu }}$ directly from EF-Tu should be investigated. The opposite problem has been proposed to happen in $A$. ferrooxidans since high levels of tetrapyrroles are synthesized in this organism. Interestingly, a particular tRNA ${ }^{\mathrm{Glu}}$ that is substrate for EF-Tu and thus for protein translation, but not for GluTR and then for tetrapyrrole biosynthesis was found in this bacteria. It is supposed that this tRNA $^{\text {Glu }}$ may ensure protein translation under conditions where high levels of heme are required. ${ }^{39}$ The gene encoding this tRNA ${ }^{\text {Glu }}$ is part, along with 36 other tRNA genes, of an integrative conjugative element that is present in strain ATCC 23270, but absent in other $A$. ferrooxidans strains. ${ }^{86,87}$ It has been proposed that the presence of tRNA genes in phages helps them to express their genes in the infected cell where the tRNA abundance may not correspond to their own codon usage. ${ }^{88}$ Thus, an alternative hypothesis for the function of this particular tRNA Glu is that it might represent a "selfish" gene of the integrative conjugative element that ensures the expression of its genes in cells where not only the tRNA abundance does not match with its own codon usage, but also the high levels of heme synthesis might prevent efficient translation.

\section{Concluding Remarks}

As discussed in the preceding pages, Glu-tRNA is the substrate of several pathways (Figure 1). Tight modulation of its formation and specific routing are required to allow the coexistence of all these metabolic routes without exposing the cell to the danger of an imbalance in aa-tRNA concentrations or the synthesis of mis-acylated tRNAs. To accomplish these requirements, each of the involved proteins recognize a different set of identity elements that allow the utilization of only the "correct kind" of Glu-tRNA (Figure 3). The formation of macromolecular complexes that compartmentalize certain functions facilitate the routing of part of Glu-tRNA to pathways less abundant than the translation machinery and prevents the leakage of intermediary products that are toxic to the cell such as Glu-tRNA ${ }^{\text {Gln }}{ }^{89}$ Nevertheless, a small leakage of Glu-tRNA ${ }^{\text {Gln }}$ or Asp-tRNA ${ }^{\text {Asn }}$ might not be as toxic as originally supposed. Although protein synthesis has an error rate of only 1 in $10000, E$. coli cells allow the incorporation of up to $\approx 10 \%$ erroneous Asp in positions of Asn, thanks to chaperons and proteases that prevent the damage produced by incorrectly folded polypeptides. ${ }^{54} \mathrm{~A}$ similar scenario is expected for Glu-tRNA ${ }^{\text {Gln }}$ as E. coli can express exogenous ND-GluRSs even though it does not have any AdT. ${ }^{33,54}$ These translation errors could be not only tolerated, but also might be beneficial under certain stressful environmental conditions similar to what have been observed for other examples of errors in translation. Amino acid "mis-incorporation" has been proposed to protect cells from oxidative stress through the incorporation of extra methionines in proteins or from the immune system by enhancing the antigen variability. ${ }^{90-92}$

Thus, modulation of the transamidosome complex formation could regulate the mis-incorporation of Asp and Glu in translation helping cells to survive under certain stress conditions. Analogously, macromolecular complexes with Glu-tRNA could also play a role in the regulation of cellular metabolism. For instance, the modulation of the stability of a putative GluRS-GlutRNA ${ }^{\text {Glu }}$-GluTR complex could control the fluxes of Glu-tRNA ${ }^{\text {Glu }}$ between tetrapyrrole and protein synthesis. Alternatively, an interplay between EF-Tu and GluTR affected by environmental conditions might also contribute to the balance between protein and tetrapyrrole biosynthesis.

Acknowledgements. We thank Dr. Michael Ibba and Dr. Verónica Bravo for helpful discussions. A.K. was recipient of fellowships from Conicyt, Chile and Universidad de Chile. This work was supported by Grants Fondecyt 1070437 and 1110203 from Conicyt, Chile (O.O.) 


\section{REFERENCES}

1. M. Ibba, H. D. Becker, C. Stathopoulos, D. L. Tumbula, and D. Söll, Trends Biochem. Sci. 25 (2000) 311-316.

2. M. Ibba and D. Söll, Genes \&Dev. 18 (2004) 731-738.

3. C. S. Francklyn and A. Minajigi, FEBS Lett. 584 (2010) 366-375.

4. R. Banerjee, S. Chen, K. Dare, M. Gilreath, M. Praetorius-Ibba, M. Raina, N. M. Reynolds, T. Rogers, H. Roy, S. S. Yadavalli, and M. Ibba, FEBS Lett. 584 (2010) 387-395.

5. O. Nureki, D. G. Vassylyev, K. Katayanagi, T. Shimizu, S. Sekine, T. Kigawa, T. Miyazawa, S. Yokoyama, and K. Morikawa, Science 267 (1995) 1958-1965.

6. D. Y. Dubois, J. Lapointe, and S. Sekine, Glutamyl-tRNA Synthetases, in: M. Ibba, C. Francklyn, and S. Cusack, (Eds.), The Aminoacyl-tRNA Synthetases, Landes Bioscience, Georgetown, TX, USA, 2005, pp. 89-98.

7. J. O. Schulze, A. Masoumi, D. Nickel, M. Jahn, D. Jahn, W. D. Schubert, and D. W. Heinz, J. Mol. Biol. 361 (2006) 888-897.

8. T. Ito, N. Kiyasu, R. Matsunaga, S. Takahashi, and S. Yokoyama, Acta Crystallogr. D Biol. Crystallogr. 66 (2010) 813-820.

9. S. Sekine, O. Nureki, D. Y. Dubois, S. Bernier, R. Chênevert, J. Lapointe, D. G. Vassylyev, and S. Yokoyama, EMBO J. 22 (2003) 676-688.

10. S. Sekine, M. Shichiri, S. Bernier, R. Chênevert, J. Lapointe, and S. Yokoyama, Structure 14 (2006) 1791-1799.

11. A. Sethi, J. Eargle, A. A. Black, and Z. Luthey-Schulten, P. Natl. Acad. Sci. USA 106 (2009) 6620-6625.

12. S. Dasgupta, R. Saha, C. Dey, R. Banerjee, S. Roy, and G. Basu, FEBS Lett. $\mathbf{5 8 3}$ (2009) 2114-2120.

13. D. Y. Dubois, S. P. Blais, J. L. Huot, and J. Lapointe, Biochemistry 48 (2009) 6012-6021.

14. L. Randau, S. Schauer, A. Ambrogelly, J. C. Salazar, J. Moser, S. Sekine, S. Yokoyama, D. Söll, and D. Jahn, J. Biol. Chem. 279 (2004) 34931-34937.

15. J. C. Salazar, A. Ambrogelly, P. F. Crain, J. A. McCloskey, and D. Söll, P. Natl. Acad. Sci. USA 101 (2004) 7536-7541.

16. D. Y. Dubois, M. Blaise, H. D. Becker, V. Campanacci, G. Keith, R. Giegé, C. Cambillau, J. Lapointe, and D. Kern, P. Natl. Acad. Sci. USA 101 (2004) 7530-7535

17. M. Blaise, H. D. Becker, G. Keith, C. Cambillau, J. Lapointe, R. Giegé, and D. Kern, Nucleic Acids Res. 32 (2004) 2768-2775.

18. M. Blaise, H. D. Becker, J. Lapointe, C. Cambillau, R. Giegé, and D. Kern, Biochimie 87 (2005) 847-861.

19. S. Sekine, O. Nureki, K. Sakamoto, T. Niimi, M. Tateno, M. Go, T. Kohno, A. Brisson, J. Lapointe, and S. Yokoyama, J. Mol. Biol. 256 (1996) 685-700.

20. S. Sekine, O. Nureki, M. Tateno, and S. Yokoyama, Eur. J. Biochem. 261 (1999) 354-360.

21. D. L. Tumbula, H. D. Becker, W. Z. Chang, and D. Söll, Nature 407 (2000) 106-110.

22. A. W. Curnow, K. Hong, R. Yuan, S. Kim, O. Martins, W. Winkler, T. M. Henkin, and D. Söll. P. Natl. Acad. Sci. USA 94 (1997) 11819-11826.

23. A. Schön, C. G. Kannangara, S. Gough, and D. Söll, Nature 331 (1988) 187-190.

24. C. Pujol, M. Bailly, D. Kern, L. Maréchal-Drouard, H. Becker, and A. M. Duchêne. P. Natl. Acad. Sci. USA 105 (2008) 6481-6485.

25. M. Frechin, B. Senger, M. Brayé, D. Kern, R. P. Martin, and H. D. Becker, Genes Dev. 23 (2009) 1119-1130.

26. J. R. Brown and W. F. Doolittle, J. Mol. Evol. 49 (1999) 485-495.

27. M. Siatecka, M. Rozek, J. Barciszewski, and M. Mirande, Eur. J Biochem. 256 (1998) 80-87.

28. V. Lamour, S. Quevillon, S. Diriong, V. C. N'Guyen, M. Lipins- ki, and M. Mirande, P. Natl. Acad. Sci. USA 91 (1994) 8670-8674

29. J. C. Salazar, I. Ahel, O. Orellana, D. Tumbula-Hansen, R. Krieger, L. Daniels, and D. Söll, P. Natl. Acad. Sci. USA 100 (2003) 13863-13868

30. S. Skouloubris, L. Ribas de Pouplana, H. De Reuse, and T. L. Hendrickson, P. Natl. Acad. Sci. USA 100 (2003) 11297-11302.

31. G. Levicán, A. Katz, M. de Armas, H. Núñez, and O. Orellana, P. Natl. Acad. Sci. USA 104 (2007) 3135-3140.

32. J. Lapointe, L. Duplain, and M. Proulx, J. Bacteriol. 165 (1986) 88-93.

33. H. Núñez, C. Lefimil, B. Min, D. Söll, and O. Orellana, FEBS Lett. 557 (2004) 133-135.

34. S. Sekine, O. Nureki, A. Shimada, D. G. Vassylyev, and S. Yokoyama, Nat. Struct. Biol. 8 (2001) 203-206.

35. T. Ito and S. Yokoyama, Nature 467 (2010) 612-616.

36. J. Lee and T. L. Hendrickson, J. Mol. Biol. 344 (2004) 1167-1174

37. M. Blaise, V. Olieric, C. Sauter, B. Lorber, B. Roy, S. Karmakar, R. Banerjee, H. D. Becker, and D. Kern. J. Mol. Biol. 381 (2008) 1224-1237

38. K. M. Chang and T. L. Hendrickson, Nucleic Acids Res. 37 (2009) 6942-6949.

39. G. Levicán, A. Katz, P. Valenzuela, D. Söll, and O. Orellana, FEBS Lett. 579 (2005) 6383-6387.

40. K. Sheppard, J. Yuan, M. J. Hohn, B. Jester, K. M. Devine, and D. Söll, Nucleic Acids Res. 36 (2008) 1813-1825.

41. A. W. Curnow, D. L. Tumbula, J. T. Pelaschier, B. Min, and D. Söll, P. Natl. Acad. Sci. USA 95 (1998) 12838-12843.

42. H. D. Becker and D. Kern, P. Natl. Acad. Sci. USA 95 (1998) 12832-12837.

43. G. Raczniak, H. D. Becker, B. Min, and D. Söll, J. Biol. Chem 276 (2001) 45862-45867.

44. L. Feng, K. Sheppard, D. Tumbula-Hansen, and D. Söll, J. Biol. Chem. 280 (2005) 8150-8155.

45. A. Nakamura, M. Yao, S. Chimnaronk, N. Sakai, and I. Tanaka Science 312 (2006) 1954-1958.

46. H. Oshikane, K. Sheppard, S. Fukai, Y. Nakamura, R. Ishitani, T. Numata, R. L. Sherrer, L. Feng, E. Schmitt, M. Panvert, S. Blanquet, Y. Mechulam, D. Söll, and O. Nureki, Science 312 (2006) 1950-1954.

47. E. Schmitt, M. Panvert, S. Blanquet, and Y. Mechulam, Structure 13 (2005 ) 1421-1433.

48. M. Bailly, M. Blaise, B. Lorber, H. D. Becker, and D. Kern, Mol. Cell. 28 (2007) 228-239.

49. T. Rampias, K. Sheppard and D. Söll, Nucleic Acids Res. 38 (2010) 5774-5783.

50. J. L. Huot, F. Fischer, J. Corbeil, E. Madore, B. Lorber, G. Diss, T. L. Hendrickson, D. Kern, and J. Lapointe, Nucleic Acids Res. 39 (2011) 9306-9315.

51. M. Stanzel, A. Schön, and M. Sprinzl, Eur. J. Biochem. 219 (1994) 435-439.

52. H. Roy, H. D. Becker, M. H. Mazauric, and D. Kern, Nucleic Acids Res. 35 (2007) 3420-3430.

53. T. J. Cathopoulis, P. Chuawong, and T. L. Hendrickson, Biochemistry 47 (2008) 7610-7616.

54. B. Ruan, S. Palioura, J. Sabina, L. Marvin-Guy, S. Kochhar, R. A. Larossa and D. Söll, P. Natl. Acad. Sci. USA 105 (2008) 16502-16507.

55. H. Bhaskaran and J. J. Perona, J. Mol. Biol. 411 (2011) 854-869.

56. M. Blaise, M. Bailly, M. Frechin, M. A. Behrens, F. Fischer, C. L. Oliveira, H. D. Becker, J. S. Pedersen, S. Thirup, and D. Kern. EMBO J. 29 (2010) 3118-3129.

57. M. Bailly, S. Giannouli, M. Blaise, C. Stathopoulos, D. Kern, and H. D. Becker, Nucleic Acids Res. 34 (2006) 6083-6094.

58. A. Nakamura, K. Sheppard, J. Yamane, M. Yao, D. Söll, and I. Tanaka, Nucleic Acids Res. 38 (2010) 672-682. 
59. P. Nissen, M. Kjeldgaard, S. Thirup, G. Polekhina, L. Reshetnikova, B. F. Clark, and J. Nyborg, Science 270 (1995) 1464-1472.

60. P. Nissen, S. Thirup, M. Kjeldgaard, and J. Nyborg, Structure 7 (1999) 143-156.

61. F. J. LaRiviere, A. D. Wolfson, and O. C. Uhlenbeck, Science 294 (2001) 165-168.

62. T. Dale, L. E. Sanderson, and O. C. Uhlenbeck, Biochemistry 43 (2004) 6159-6166.

63. M. R. O'Brian and L. Thöny-Meyer, Adv. Microb. Physiol. 46 (2002) 257-318.

64. I. U. Heinemann, M. Jahn, and D. Jahn, Arch. Biochem. Biophys. 474 (2008) 238-251.

65. J. Moser, S. Lorenz, C. Hubschwerlen, A. Rompf, and D. Jahn, J. Biol. Chem. 274 (1999) 30679-30685.

66. S. Schauer, S. Chaturvedi, L. Randau, J. Moser, M. Kitabatake, S. Lorenz, E. Verkamp, W. D. Schubert, T. Nakayashiki, M. Murai, K. Wall, H. U. Thomann, D. W. Heinz, H. Inokuchi, D. Söll, and D. Jahn, J. Biol. Chem. 277 (2002) 48657-48663.

67. A. Srivastava and S. I. Beale, J. Bacteriol. 187 (2005) 4444-4450.

68. M. de Armas-Ricard, G. Levicán, A. Katz, J. Moser, D. Jahn, and O. Orellana, Biochem. Biophys. Res. Commun. 405 (2011) 134-139.

69. J. Moser, W. D. Schubert, V. Beier, I. Bringemeier, D. Jahn, and D. W. Heinz, EMBO J. 20 (2001) 6583-6590.

70. C. Lüer, S. Schauer, K. Möbius, J. Schulze, W. D. Schubert, D. W. Heinz, D. Jahn, and J. Moser, J. Biol. Chem. 280 (2005) $18568-18572$.

71. L. A. Nogaj and S. I. Beale, J. Biol. Chem. 280 (2005) 24301-24307.

72. R. D. Willows, C. G. Kannangara, and B. Pontoppidan, Biochim. Biophys. Acta. 1263 (1995) 228-234.

73. G. P. O'Neill, D. M. Peterson, A. Schön, M. W. Chen, and D. Söll, J. Bacteriol. 170 (1988) 3810-3816.

74. C. Lüer, S. Schauer, S. Virus, W. D. Schubert, D. W. Heinz, J. Moser, and D. Jahn, FEBS J. 274 (2007) 4609-4614.

75. P. Choi, L. Wang, C. D. Archer, and T. Elliott, J. Bacteriol. 178 (1996) 638-646.

76. R. Krieger, A. Rompf, M. Schobert, and D. Jahn, Mol. Genet
Genomics 267 (2002) 409-417.

77. J. Frunzke, C. Gätgens, M. Brocker, and M. Bott, J. Bacteriol. 193 (2011) 1212-1221.

78. L. Wang, L. Brown, M. Elliott, and T. Elliott, J. Bacteriol. 179 (1997) 2907-2914.

79. L. Wang, M. Elliott, and T. Elliott, J. Bacteriol. 181 (1999) 6033-6041.

80. L. Wang, M. Elliott, and T. Elliott, J. Bacteriol. 181 (1999) 1211-1219.

81. A. M. Jones and T. Elliott, FEMS Microbiol. Lett. 307 (2010) 41-47.

82. A. Katz, R. Banerjee, M. de Armas, M. Ibba, and O. Orellana, Biochem. Biophys. Res. Commun. 398 (2010) 51-55.

83. D. Jahn, FEBS Lett. 314 (1992) 77-80.

84. S. Paravisi, G. Fumagalli, M. Riva, P. Morandi, R. Morosi, P. V. Konarev, M. V. Petoukhov, S. Bernier, R. Chênevert, D. I. Svergun, B. Curti, and M. A. Vanoni, FEBS J. 276 (2009) 1398-1417.

85. J. Ling, B. R. So, S. S. Yadavalli, H. Roy, S. Shoji, K. Fredrick, K. Musier-Forsyth, and M. Ibba, Mol. Cell 33 (2009) 654-660.

86. G. Levicán, A. Katz, J. Valdés, R. Quatrini, D. S. Holmes, and O. Orellana, Advanced Materials Research 71-73 (2009) 187-190.

87. P. Bustamante and O. Orellana personal communication.

88. M. Bailly-Bechet, M. Vergassola, and E. Rocha, Genome Res. 17 (2007) 1486-1495.

89. M. H. Barros, M. Rak, J. A. Paulela, and Tzagoloff, J. Biol. Chem. 286 (2011) 32937-32947.

90. M. Meyerovich, G. Mamou, and S. Ben-Yehuda, P. Natl. Acad. Sci. USA 107 (2010) 11543-11548.

91. N. Netzer, J. M. Goodenbour, A. David, K. A. Dittmar, R. B. Jones, J. R. Schneider, D. Boone, E. M. Eves, M. R. Rosner, J. S. Gibbs, A. Embry, B. Dolan, S. Das, H. D. Hickman, P. Berglund, J. R. Bennink, J. W. Yewdell, and T. Pan, Nature 462 (2009) 522-526.

92. L. Li, M. T. Boniecki, J. D. Jaffe, B. S. Imai, P. M. Yau, Z. A. Luthey-Schulten, and S. A. Martinis, P. Natl. Acad. Sci. USA 108 (2011) 9378-9383.

93. E. Krissinel and K. Henrick, J. Mol. Biol. 372 (2007) 774-797. 